\title{
Aortic nightmares: Can we sleep better?
}

\author{
John W. Hammon, MD
}

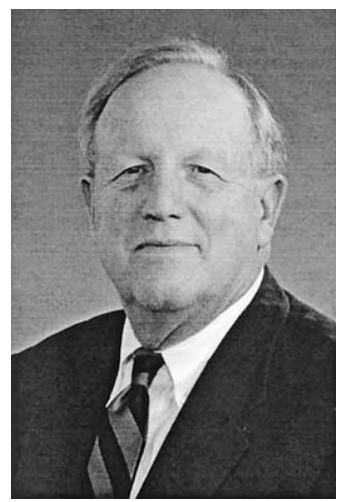

See related article on page 1451.

From the Wake Forest University Health Sciences, Winston-Salem, NC.

Received for publication Sept 10, 2002; accepted for publication Sept 17, 2002.

Address for reprints: John W. Hammon, Professor of Surgery, Wake Forest University Health Sciences, Medical Center Boulevard, Winston-Salem, NC 27157-1096. (E-mail: jhammon@wfubmc.edu).

J Thorac Cardiovasc Surg 2003;125:1200-1

Copyright () 2003 by The American Association for Thoracic Surgery

$0022-5223 / 2003 \$ 30.00+0$

doi:10.1016/S0022-5223(02)73574-5

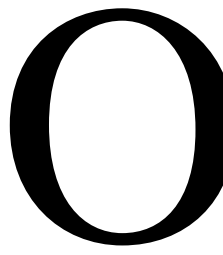

ne of the recurring nightmares facing surgeons who operate on the thoracic aorta involves incising the aorta and visualizing severe degenerative atherosclerosis with toothpaste-like material in the wall of the aorta and the interior of the aorta lined with ulcerations containing platelet, fibrin strands, and, in some cases, actual blood clots. If a clamp is applied to this aorta, it is not difficult to imagine this material breaking away and embolizing to vital organs, causing severe complications. As the authors of "Embolic material generated by multiple aortic crossclamping: A perfusion model with human cadaveric aorta" point out, repeated clamping of atherosclerotic aortas releases not only calcified atherosclerotic debris, but smaller emboli consistent with cellular debris as well. On the basis of their data, it is hard to believe that any patient with aortic atherosclerosis, who undergoes surgery involving aortic clamping, does not end up with some permanent, severe organ damage related to intraoperative embolization.

Fortunately, a quick review of the cardiac surgery literature would suggest that the incidence of permanent stroke, renal failure, and other severe organ damage and death are quite low in clinical cardiac surgery today, ${ }^{1,2}$ although it has been pointed out by a number of authors that risk factors for organ damage during cardiopulmonary bypass are greatly amplified by the presence of severe atherosclerosis of the thoracic aorta and its branches. ${ }^{3,4}$ What then can be done to minimize the risk of potential embolization and what is the future for cardiopulmonary bypass in patients with severe aortic atherosclerosis?

As we have shown from data collected in patients from our own institution, and others have likewise pointed out, patients with palpable aortic atherosclerosis have a higher incidence of ultrasound-detected emboli during cardiac surgery. ${ }^{5,6}$ There is no question that surgeons strive to avoid placing crossclamps and perform other aortic manipulations across areas of palpable atherosclerosis. As Davila-Roman and his group have pointed out, however, all aortic atherosclerosis is not palpable. ${ }^{7}$ They have popularized a technique of epiaortic ultrasound scanning to map the aorta in areas of potential manipulation to determine whether atherosclerotic material is present. These techniques have become more widespread throughout the cardiac surgical community and, when combined with transesophageal echocardiography, give the surgeon a concrete idea of the presence of atherosclerosis in areas where clamps or incisions may be applied. Thus, it is possible to manipulate the aorta in areas where atherosclerosis is not present in the vast majority of cases. It appears from the data given to us by Boivie and colleagues ${ }^{8}$ that the one patient without calcified atherosclerosis had many fewer potential emboli, even on repeated clamping. Thus, we must focus our attention on patients with detectable, severe atherosclerosis.

What is the surgeon to do if the aorta is extensively diseased? Fortunately, there are many solutions for patients, particularly undergoing CABG operation. A popular option to avoid cannulation and pump flow-induced aortic trauma is to perform off-pump operations. Even in these operations, aortic manipulation, especially with partial occlusion clamps, must be avoided as emphasized by Calafiore and associates. ${ }^{9}$ Grafts may be based off the internal mammary artery and the only chance for aortic manipulation is when the heart is distracted to provide access to vessels on the obtuse margin and posterior and inferior walls of the heart. If the surgeon chooses to use cardiopulmonary bypass, a no-touch technique may be utilized by allowing the heart to remain beating or fibrillating and the same intraoperative stabilization 
maintained for anastomoses, as is used in off-pump surgery. If aorto-coronary grafts must be used, newer anastomotic devices are available to avoid clamping the aorta during the aorto-saphenous vein anastomosis. ${ }^{10}$ If the ascending aorta is somewhat diseased but a free area can be mapped by ultrasound, a single-clamp technique can be utilized to perform all distal and proximal anastomoses. This technique has been shown to reduce the incidence of postoperative neuropsychological deficits following CABG surgery. ${ }^{11}$ Rarely, the ascending aorta can be resected and replaced with a graft, which then can be used to base aorto-coronary grafts, as suggested by Kouchoukos and coworkers. ${ }^{12}$

During aortic valve operations, the aorta must be clamped and incised; thus patients with significant ascending aortic atherosclerosis present a difficult problem. A technique utilizing a short period of circulatory arrest combined with resection and graft replacement of this portion of the aorta has been successfully combined with aortic valve replacement and avoids the difficult problem of suturing and manipulating the calcified, atherosclerotic ascending aorta during aortic valve replacement. ${ }^{13}$

The article by Boivie and colleagues is simple in its methodology but the potential impact of the research is blunted because of the small number of aortas tested and the marked variability of numbers and size of potential emboli released. Despite these limitations the results remind the surgeon that repeated aortic crossclamping in patients with atherosclerotic aortas is potentially dangerous. If one absolutely has to clamp the atherosclerotic aorta, can technology come to the rescue? Devices are now under development that may offer some relief from atherosclerotic embolism. Cannulas with improved flow characteristics and/or balloons to isolate the ascending aorta from the remainder of the circulation, such that clamps do not have to be applied, are now becoming commercially available but have not been rigorously tested. Devices that partition the aorta into a craniocervical division and a corporal division are under development, which offer the possibility of directing potential emboli away from the head and also allowing a protocol in which the head is selectively cooled to minimize embolic injury. ${ }^{14}$ Filter devices are being tested, which may offer the ability to trap emboli from the ascending aorta to avoid damage to critical organs. ${ }^{15}$
Although it could be said that the data presented by Boivie and colleagues remind us of something we already know and would rather forget, it is also true that this type of research with simple design and obvious conclusions allows surgeons to modify techniques such that they sleep better and enjoy improved outcomes in very sick patients.

\section{References}

1. Jamieson WRE, Edwards FH, Schwartz M, Bero JW, Clark RE, Grover FL. Risk stratification for cardiac valve replacement. National Cardiac Surgery Database. Ann Thorac Surg. 1999;67:943-51.

2. Edwards FH, Clark RE, Schwartz M. Coronary artery bypass grafting: the Society of Thoracic Surgeons National Database experience. Ann Thorac Surg. 1994;57:12-9.

3. Blauth CL, Cosgrove DM, Webb BW. Atheroembolism from the ascending aorta. An emerging problem in cardiac surgery. $J$ Thorac Cardiovasc Surg. 1992;103:1104-12.

4. Goto T, Baba T, Yoshitake A, Shibata Y, Ura M, Sakata R. Craniocervical and aortic atherosclerosis as neurologic risk factors in coronary surgery. Ann Thorac Surg. 2000;69:834-40.

5. Stump DA, Rogers AT, Hammon JW, et al. Cerebral emboli and cognitive outcome after cardiac surgery. J Cardiothoracic Anesth. 1996;10:1-8

6. Barbut D, Yao FS, Hager DN, Kavanaugh P, Trifiletti RR, Gold JP. Comparison of transcranial Doppler ultrasonography and transesophageal echocardiography to monitor emboli during coronary artery bypass surgery. Stroke. 1996;27:87-90.

7. Davila-Roman VG, Barzilai B, Wareing TH, Murphy SF, Kouchoukos NT. Intraoperative ultrasonographic evaluation of the ascending aorta in 100 consecutive patients undergoing cardiac surgery. Circulation. 1991;84(Suppl III):III47-53.

8. Boivie M, Hansson M, Engström KG. Embolic material generated by multiple aortic crossclamping: a perfusion model with human cadaveric aorta. J Thorac Cardiovasc Surg. 2003;125:1451-60.

9. Calafiore AM, Mauro MD, Teodori G, et al. Impact of aortic manipulation on incidence of cerebrovascular accidents after surgical myocardial revascularization. Ann Thorac Surg. 2002;73:1387-93.

10. Endo M, Benhameid O, Morin JF, Shennib H. Avoiding aortic clamping during coronary artery bypass using an automated anastomotic device. Ann Thorac Surg. 2002;73:1000-1.

11. Hammon JW, Stump DA, Kon ND, et al. Risk factors and solutions for the development of neurobehavioral changes after coronary artery bypass grafting. Ann Thorac Surg. 1997;63:1613-8.

12. Kouchoukos NT, Wareing TH, Daily BB, Murphy SF. Management of the severely atherosclerotic aorta during cardiac operations. J Card Surg. 1994;9:490-4.

13. Gillinov AM, Lytle BW, Hoang VU, et al. The atherosclerotic aorta at aortic valve replacement: surgical strategies and results. J Thorac Cardiovasc Surg. 2000;120:957-65.

14. Boston US, Sungurtekin H, Christopher GA, McGregor CGA, Macoviak JA, Cook DJ. Differential perfusion: a new technique for isolated brain cooling during cardiopulmonary bypass. Ann Thorac Surg. 2000; 69:1346-50.

15. Schmitz C, Blackstone EH. International Council of Emboli Management (ICEM) Study Group results: risk adjusted outcomes in intraaortic filtration. Eur J Cardiothorac Surg. 2001;20:986-91. 